\title{
Article
}

\section{Tactical Harvest Scheduling using Zero-one Integer Programming}

\begin{abstract}
Atsushi Yoshimoto*
\end{abstract}
\begin{abstract}
Searching for an optimal harvest scheduling regime has been a major concern of forest managers. The balance of costs and benefits of a management practice vary depending upon its efficiency. This study addresses the harvest scheduling problem with a log transportation network within the integer programming framework. A harvest scheduling system was constructed with using commercial software, CPLEX, as an optimizer to search for an optimal tactical solution. A case study was conducted using a forest management problem in Chile over a short time horizon to investigate the effect of integer restrictions on road construction and harvest decision variables on the regime. Computational comparison of a linear programming formulation and integer programming formulation showed that without considering road construction constraints in the problem formulation, serious costs may result in the management regime. Timing of the harvest of a unit may also change when integer restrictions are imposed on the harvest decision variables.
\end{abstract}

Keyword: Forest economics, harvest scheduling, mathematical programming, 0-1 integer programming, transportation network

\section{INTRODUCTION}

Harvest scheduling is a major concern of forest managers. Depending on their scheme, the balance of costs and benefits for the management varies. For long-term harvest scheduling, problems would be when and how much of forest stands should be harvested under certain constraints. Harvest timing and volume over the time horizon have been the main interests. Constraints can be the harvest flow requirements, cash flow requirements and nonmonetary resource requirements, such as wildlife protection, watershed protection and other societal concerns. This kind of long-term harvest scheduling is called a strategic harvest scheduling problem (NELSON et al. 1991). To solve a strategic problem, a forest is divided into several strata of harvest units with the same attribute. A linear programming solution technique plays a central role in solving strategic planning problems. Timber RAM

* Faculty of Agriculture, Miyazaki University, 1-1, Gakuen-kibanadai-Nishi, Miyazaki 889-21 Japan
(NAVON 1971), MUSYC (JOHNSON and JONES 1979), and FORPLAN (JOHNSON and STUART 1987) are examples of an LP based model.

A major shortcoming of the strategic planning technique is the lack of site specific information about harvest decisions. Since solutions from an LP based model are nonnegative real values, rounding techniques have to be implemented for such solutions to provide a site specific variable, even though the derived solutions may not be optimal or even feasible.

Site specific information is necessary to achieve the management regime on the working ground, especially over a short time horizon. When a harvest takes place, how much volume is harvested, which forest stand is harvested, and which logging roads have to be build, are practical and necessary problems for managers on the working ground. The problems involve such decisions as "harvest a unit"-or -"not harvest a unit", and "build a logging road"-or-"not build a logging road. This kind of problem is called a tactical harvest scheduling problem. Because of the requirements for site specific information, which is represented by dichotomous decision variables, a mix or $0-1$ integer programming (IP) solution technique is used to 
solve the problem. KONOHIRA (1982) developed the forestry oriented algorithm to solve harvest scheduling problems within the IP framework. His algorithm is basically the same as the branch-and-bound algorithm, which was introduced by LAND and DoIG (1960) and DAKIN (1965), but utilized the weighting procedure to accelerate solution speed. IRPM (KIRBY et al. 1980) was constructed to solve IP harvesting scheduling problems with a road network. Recent applications of such IP problems focus on the harvest scheduling with adjacency constraints (SEssions and SEssions 1988; TORRES 1989; NELSON and BRODIE 1990; Clements et al. 1990; ROISE 1990; NELSON et al. 1991; Yoshimoto et al. 1994; Yoshimoto and BRodie 1994), where a problem was solved by heuristics within the IP framework. This is because the computational burden is a serious problem for an exact solution algorithm for IP, e.g., the branch-and-bound algorithm.

The objective of this paper is to address a log transportation problem as a tactical harvest scheduling problem within the IP framework, then analyze the effect of the 01 integer restrictions for the decision variables on the scheduling regime. To conduct the analysis, the tactical harvest scheduling system is built in conjunction with the commercial software, CPLEX, where the branch-andbound algorithm is embedded. A case study is conducted for a timber company in Chile. The remainder of the paper is organized as follows. In the next section, the proposed tactical harvest scheduling problem is presented, then formulated in the IP framework. The tactical harvest scheduling system is constructed in the third section. In the fourth section, an effect of the $0-1$ integer restriction is presented, followed by conclusions in the fifth section.

\section{TACTICAL HARVEST SCHEDULING PROBLEM FORMULATION}

The following is the tactical harvest scheduling problem we are concerned with. The $\mathrm{X}$ forest company in Valdivia, Chile has a harvest scheduling problem over next 5 years. Harvest is conducted twice a year, in summer and winter. The company has two kinds of forests. One has been managed before, and the other has not. The tree species is Radiata pine (Pinus radiata). In the managed forests, logging roads are already built, while they have to be built for the unmanaged forests. There are several options for harvesting, i.e., to use a skidder, a logging cable, or a mechanical harvester. If a mechanical harvester is used, all harvested trees are delivered to the mill directly. This is because the harvester can harvest a tree and scribe it ready for the mill operation. Otherwise, harvested trees have to be shipped to the yard first to be scribed, then to the mill. A road construction decision in the unmanaged forests is dependent on which harvest option is used. If a skidder or a mechanical harvester is used, roads have to be constructed up to a harvest area, while a cable logging does not require such road construction. Some of the roads among harvest units, yards and mills are already built, and others are not.

As for the company's current management practice, they predicted that if they continue harvesting their mature forests at the current harvest rate, they will have a large shortage of logs in the near future. Therefore, the company decided to buy logs from third parties now to narrow the gap in the harvest flow level over time. Due to the contracts with other companies, the company has several output constraints for scheduling, i.e., pulp volume flow, sawlog volume flow and veneer volume flow constraints. Also, since the company cannot buy or sell their harvest equipment more than a certain amount, there are harvest equipment constraints. In addition, there are nonnegative cash flow constraints, and yard capacity constraints.

Under these circumstances, the company tries to allocate unmanaged and managed forests into their scheduling framework, considering road construction costs and $\log$ transportation costs to yards and mills. In what follows, the problem is formulated within the IP framework. Note that in this problem only one yard and one mill are considered. For problems with more than one yard and mill, the formulation can be easily extended.

Let us define decision variables and coefficients, then formulate the problem. In this problem, there are seventeen decision variables. The first fifteen variables are continuous, while the other two variables are $0-1$ integer variables. The continuous variables are;

$V P 3_{n, t}$ : pulp volume to be bought from the $n$-th party at time $t$

$V S 3_{n, t} \quad$ : sawlog volume to be bought from the $n$-th party at time $t$

$V V 3_{n, t}$ : veneer volume to be bought from the $n$-th party at time $t$

$X P_{i, t} \quad$ : pulp volume harvested by a skidder or cable then shipped through the $i$-th road at time $t$

$X S_{i}, t \quad$ : sawlog volume harvested by a skidder or cable then shipped through the $i$-th road at time $t$

$X V_{i, t} \quad$ : veneer volume harvested by a skidder or cable then shipped through the $i$-th road at time $t$

$X P M_{i, t}$ : pulp volume harvested by a harvester then shipped through the $i$-th road at time $t$

$X S M_{i}, t$ : sawlog volume harvested by a harvester then shipped through the $i$-th road at time $t$

$X V M_{i, t}$ : veneer volume harvested by a harvester then shipped through the $i$-th road at time $t$

$P V Y D_{t} \quad$ : pulp volume shipped to the yard at time $t$

$S V Y D_{t} \quad$ : sawlog volume shipped to the yard at time $t$

$V V Y D_{t}$ : veneer volume shipped to the yard at time $t$

$P V M L_{t}$ : pulp volume shipped to the mill at time $t$

$S V M L_{t}$ : sawlog volume shipped to the mill at time $t$ 
$V V M L_{t}$ : veneer volume shipped to the mill at time $t$

The 0-1 integer variables are;

$Z F_{i, t}= \begin{cases}1 & \text { if the } i \text {-th road is built at time } t \\ 0 & \text { otherwise }\end{cases}$

$Z O_{j, o, t}=\left\{\begin{array}{l}1 \quad \begin{array}{l}\text { if the } o \text {-th harvest option is implemented at } \\ \text { the } j \text {-th harvest at time } t\end{array} \\ 0 \quad \text { otherwise }\end{array}\right.$

Coefficients are defined as follows;

$P P_{t} \quad$ : price of pulp per unit volume at time $t$

$P S_{t} \quad$ : price of sawlog per unit volume at time $t$

$P V_{t} \quad$ : price of veneer per unit volume at time $t$

$C V_{i, t} \quad$ : variable cost per unit volume for transportation at the $i$-th road at time $t$

$C F_{i, t} \quad$ : fixed cost for the $i$-th road construction at time $t$

$C O_{j}, o, t$ : setup costs in the $j$-th harvest unit at time $t$ to carry out the harvest option $o$

$C E_{e, t} \quad$ : the $e$-th equipment usage cost at time $t$

$B P_{n, t} \quad$ : cost per unit volume to buy the $n$-th party's pulp at time $t$

$B S_{n, t} \quad$ : cost per unit volume to buy the $n$-th party's sawlog at time $t$

$B V_{n, t} \quad$ : cost per unit volume to buy the $n$-th party's veneer at time $t$

$P V L_{t} \quad$ : lower bound of pulp flow at time $t$

$P V U_{t} \quad$ : upper bound of pulp flow at time $t$

$S V L_{t} \quad$ : lower bound of sawlog flow at time $t$

$S V U_{t} \quad$ : upper bound of sawlog flow at time $t$

$V V L_{t} \quad$ : lower bound of veneer flow at time $t$

$V V U_{t} \quad$ : upper bound of veneer flow at time $t$

$S P V_{k, j}, o, t$ : pulp volume obtained by the $o$-th harvest option using a skidder or cable at the $j$-th harvest unit, then shipped to the $k$-th node at time $t$

$S S V_{k, j, o, \mathrm{t}}$

sawlog volume obtained by the $o$-th harvest option using a skidder or cable at the $j$-th harvest unit, then shipped to the $k$-th node at time $t$

$S V V_{k}, j, o$, $t$ : veneer volume obtained by the $o$-th harvest option using a skidder or cable at the $j$-th harvest unit, then shipped to the $k$-th node at time $t$

$S P V M_{b j, a, i}$ pulp volume obtained by the $o$-th harvest option using a harvester at the $j$-th harvest unit to the $k$-th node at time $t$

$S S V M_{k, j, a}$ isawlog volume obtained by the $o$-th harvest option using a harvester at the $j$-th harvest unit to the $k$-th node at time $t$

$S V V M_{k, j, a}$, veneer volume obtained by the $o$-th harvest option using a harvester at the $j$-th harvest unit to the $k$-th node at time $t$

$A R E A_{j}$ : area (ha) of the $j$-th harvest unit

$W V_{j, t} \quad$ : weighting value to reflect a future value of the $j$

-th harvest unit after harvesting the unit at time $t$ ( this could be soil expectation value of that unit)

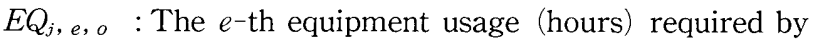
the $o$-th harvest option at the $j$-th harvest unit

$H E L_{e}, t$ : lower bound of the $e$-th harvest equipment utility at time $t$

$H E U_{e, t}$ : upper bound of the $e^{\text {-th }}$ harvest equipment utility at time $t$

$P 3 U_{t} \quad$ : upper bound of pulp volume available from the third parties at time $t$

$S 3 U_{t} \quad$ : upper bound of sawlog volume available from the third parties at time $t$

$V 3 U_{t} \quad$ : upper bound of veneer volume available from the third parties at time $t$

$Y C \quad$ : yard capacity

$r \quad$ : discount rate

$M \quad$ : a given large number

A : a node-arc incidence matrix for skidder or cable $\log$ delivery defined by

$A_{i, j}=\left\{\begin{aligned} 1 & \text { if } \operatorname{arc} j \text { is directed away from node } i \\ -1 & \text { if } \operatorname{arc} j \text { is directed toward node } i \\ 0 & \text { otherwise }\end{aligned}\right.$

(Note: no connection to a mill from any node, but from a yard)

AM : a node-arc incidence matrix for harvester $\log$ delivery defined by

$A M_{i},{ }_{j}=\left\{\begin{aligned} 1 & \text { if } \operatorname{arc} j \text { is directed away from node } i \\ -1 & \text { if } \operatorname{arc} j \text { is directed toward node } i \\ 0 & \text { otherwise }\end{aligned}\right.$

(Note: no connection from any node to a yard)

$E \quad$ : the number of harvest equipments

$I \quad$ : the number of roads (arcs)

$J \quad$ : the number of harvest units

$K \quad$ : the number of nodes

$N \quad$ : the number of third parties

$O_{j} \quad$ : the number of harvest options for the $j$-th harvest unit

$T \quad$ : the number of periods for planning

The objective of the proposed harvest scheduling problem is to maximize the total present net value from selling pulp, sawlog and veneer, minus transportation costs consisting of variable costs (or delivery costs) and fixed costs (road construction costs), minus setup costs, minus harvest equipment use costs, minus costs of buying the third parties' pulp, sawlog and veneer, and plus the weighting value of remaining stands. This weighting value is a user defined value and could be soil expectation value of a stand after harvesting. This is considered in the objective function to reflect a future return of the stand because harvesting in the proposed problem is implemented only once over 5 years.

$\max J=\sum_{t=1}^{T} \frac{1}{(1+r)^{t-1}}\left\{P P_{t}\left(P V M L_{t}+\sum_{n=1}^{N} V P 3_{n, t}\right)+P S_{t}\left(S V M L_{t}+\sum_{n=1}^{N} V S 3_{n, t}\right)\right.$ 


$$
\begin{aligned}
& \left.+P V_{t}\left(V V M L_{t}+\sum_{n=1}^{N} V V 3_{n, t}\right)\right\} \\
& -\sum_{i=1}^{T} \sum_{t=1}^{T} \frac{C V_{i, t}}{(1+r)^{t-1}}\left(X P_{i, t}+X S_{i, t}+X V_{i, t}+X P M_{i, t}+X S M_{i, t}+X V M_{i, t}\right) \\
& -\sum_{i=1}^{I} \sum_{t=1}^{T} \frac{C F_{i, t}}{(1+r)^{t-1}} Z F_{i, t} \\
& -\sum_{j=1}^{J} \sum_{t=1}^{T} \sum_{0=1}^{o j} \frac{C O_{j, 0, t}}{(1+r)^{t-1}} Z O_{j, 0, t} \\
& -\sum_{j=1}^{T} \sum_{t=1}^{T} \sum_{e=1}^{E} \sum_{0=1}^{o j} \frac{C E_{e, t}}{(1+r)^{t-1}} E Q_{j, e, 0} \cdot Z O_{j, o, t} \\
& +\sum_{j=1}^{J} \sum_{t=1}^{T} \sum_{0=1}^{o_{j}} \frac{W V_{j, t}}{(1+r)^{t-1}} Z O_{j, t, o} \\
& -\sum_{n=1}^{N} \sum_{t=1}^{T}\left\{\frac{B P_{n, t}}{(1+r)^{t-1}} V P 3_{n, t}+\frac{B S_{n, t}}{(1+r)^{t-1}}+\frac{B V_{n, t}}{(1+r)^{t-1}} V V 3_{n, t}\right\}
\end{aligned}
$$

The following constraints are embedded.

1: Constraints for one time road construction:

This constraint requires for all roads to be constructed at most once over the time horizon.

$$
\sum_{t=1}^{T} Z F_{i, t} \leq 1 \text { for } i=1,, I
$$

2: Road linkage constraints for one-directional transshipment:

If there is only one road directed toward the mill or the yard from any road connection, (node), the incoming roads to the node have to be built before the outgoing road.

$$
\sum_{t=1}^{t_{1}} Z F_{i, t}-Z F_{j, t_{1}} \geq 0 \text { for } t_{1}=1,, T
$$

where the $j$-th road (arc) is the incoming road and the $i$ th road $(\operatorname{arc})$ is the outgoing road. If there is more than one road directed toward the mill or yard, it is not necessary to have this constraint for that incoming road. A road construction constraint for such a road is dealt with in the fifth constraint.

3: Simultaneous log transportation constraints:

There can be multiple entrances to one harvest unit. In such cases, implementation of a harvest option results in $\log$ transportation to several entrances connected to roads at the same time. Thus, construction of such roads has to be achieved simultaneously.

$$
Z F_{i, t}-Z F_{j, t}=0 \text { for } t=1,, T
$$

where the $i$ - and $j$-th roads (arcs) are an end road directly connected to the same harvest unit, and share the concurrent $\log$ transportation.

4: Harvest unit and road linkage constraints:

Construction of roads, which is necessary for each harvest option, has to be achieved before transporting logs from a harvest unit

$$
\sum_{t=1}^{t_{1}} Z F_{i, t}-Z O_{j, o, t_{1}} \geq 0 \text { for } \forall o \in O_{j}, t_{1}=1, T, j=1,, J
$$

where the $i$-th road ( $\operatorname{arc}$ ) is connected to the $j$-th harvest unit, and the $o$-th option requires shipment through the $i^{-}$ th road first.

5: Constraints for road construction before shipping logs:

A road has to be constructed before any shipment of logs. Note that such a road is not taken into consideration in the second constraints described above. This is a common constraint formulation on the relationship between variable costs and fixed costs for transportation problems.

$$
X P_{i, t}+X S_{i, t}+X V_{i, t}+X P M_{i, t}+X S M_{i, t}+X V M_{i, t}-M \sum_{l=1}^{t} Z F_{i, l} \leq 0 \text { for } i=1, I, t=1, T
$$

where $M$ is the maximum harvest flow for the $i$-th road or a given large number. The first three terms on the left hand side are for logs harvested by skidders or cables, and the next three terms are for harvesters.

6: Node-arc linkage constraints:

This is a constraint for shipment of logs through nodes and arcs. Note that nodes are such points that connect roads and an arc is equivalent to a road.

$$
\sum_{i=1}^{I} A_{k, t} \cdot X P_{i, t}-\sum_{j=1}^{J} \sum_{o=1}^{o_{j}} S P V_{k, j, o, t} \cdot Z O_{j, 0, t}=0 \text { for } k=1, K-2, t=1, T
$$

$$
\sum_{i=1}^{I} A_{k, i} \cdot X S_{i, t}-\sum_{j=1}^{l} \sum_{o=1}^{o_{j}} S S V_{k, j, 0, t} \cdot Z O_{j, o, t}=0 \text { for } k=1, K-2, t=1,, T
$$

$$
\sum_{i=1}^{I} A_{k, i^{*}} \cdot X V_{i, t^{-}} \sum_{j=1}^{J} \sum_{o=1}^{O_{j}} S V V_{k, j, o, t} \cdot Z O_{j, o, t}=0 \text { for } k=1, K-2, t=1,, T
$$

$$
\sum_{i=1}^{l} A M_{k, \cdot} \cdot X P M_{i, t}-\sum_{j=1}^{j} \sum_{o=1}^{o_{j}} S P V M_{k, j, o, t} \cdot Z O_{j, o, t}=0 \text { for } k=1, K-2, t=1,, T
$$

$$
\sum_{i=1}^{I} A M_{k, i} \cdot X S M_{i, t}-\sum_{j=1}^{l} \sum_{o=1}^{o_{j}} \operatorname{SSVM}_{k, j, o, t} \cdot Z O_{j, o, t}=0 \text { for } k=1, K-2, t=1,, T
$$

$$
\sum_{i=1}^{l} A M_{k, t} \cdot X V M_{i, t}-\sum_{j=1}^{J} \sum_{o=1}^{O_{j}} S V V M_{k, j, 0, t} \cdot Z O_{j, o, t}=0 \text { for } k=1, K-2, t=1,, T
$$

Note that the $(K-1)$-st node is the yard, and the $K$-th node is the mill. The node-arc linkage constraints for those are considered in the ninth and tenth constraints later.

7: Area constraints for harvest units: 
The harvested area cannot exceed its own total area. The sum of harvested areas for each unit must be less than or equal to its total area.

$$
A R E A_{j} \cdot \sum_{t=1}^{T} \sum_{o=1}^{O_{j}} Z O_{j, o, t} \leq A R E A_{j} \text { for } j=1, J
$$

8: Nonnegative cash flow constraints:

This requires a nonnegative cash flow at each period. Cash flow consists of benefits from selling pulp, sawlog, and veneer, and such costs as fixed and variable transportation costs, setup costs, equipment usage costs, and costs to buy products from the third parties.

$$
\begin{aligned}
& P P_{t}\left(P V M L_{t}+\sum_{n=1}^{N} V P 3_{n, t}\right)+P S_{t}\left(S V M L_{t}+\sum_{n=1}^{N} V S 3_{n, t}\right)+P V_{t}\left(V V M L_{t}+\sum_{n=1}^{N} V V 3_{n, t}\right) \\
& -\sum_{i=1}^{I} C V_{i, t}\left(X P_{i, t}+X S_{i, t}+X V_{i, t}+X P M_{i, t}+X S M_{i, t}+X V M_{i, t}\right) \\
& -\sum_{i=1}^{I} C F_{i, t} \cdot Z F_{i, t} \\
& -\sum_{j=1}^{J} \sum_{o=1}^{O_{j}} C O_{j, 0, t} \cdot Z O_{j, o, t} \\
& -\sum_{j=1}^{J} \sum_{e=1}^{E} \sum_{j=1}^{O_{j}} C E_{e, t} \cdot E Q_{j, e, o} \cdot Z O_{j, 0, t} \\
& -\sum_{n=1}^{N}\left\{B P_{n, t} \cdot V P 3_{n, t}+B S_{n, t} \cdot V S 3_{n, t}+B V_{n, t} \cdot V V 3_{n, t}\right\} \\
& \geq 0 \text { for } t=1, T
\end{aligned}
$$

9: Constraints for logs shipped to the yard at each period: Logs can be left over at the yard, or shipped to the mill.

$$
\begin{aligned}
& \sum_{i=1}^{I} A_{k-1, i} \cdot X P_{i, t}+P V Y D_{t}-P V Y D_{t-1}=0 \text { for } t=1,, T \\
& \sum_{i=1}^{I} A_{k-1, i} \cdot X S_{i, t}+S V Y D_{t}-S V Y D_{t-1}=0 \text { for } t=1,, T \quad(16) \\
& \sum_{i=1}^{I} A_{k-1, i} \cdot X S_{i, t}+V V Y D_{t}-V V Y D_{t-1}=0 \text { for } t=1, T \quad(17)
\end{aligned}
$$$$
P V Y D_{0}=S V Y D_{0}=V V Y D_{0}=0
$$

Note that no log harvested by a mechanical harvester goes to the yard, the $(K-1)$-st node.

10: Constraints for logs shipped to the mill at each period:

Logs are shipped to the mill either from the yard, or by other roads only if a mechanical harvester is used for harvesting.

$$
\begin{aligned}
& \sum_{i=1}^{I} A_{K i} \cdot X P_{i, t}+\sum_{i=1}^{I} A M_{K, i} \cdot X P M_{i, t}+P V M L_{t}=0 \text { for } t=1, T \\
& \sum_{i=1}^{I} A_{K i} \cdot X S_{i, t}+\sum_{i=1}^{I} A M_{K, i} \cdot X S M_{i, t}+S V M L_{t}=0 \text { for } t=1,, T \\
& \sum_{i=1}^{I} A_{K i} \cdot X V_{i, t}+\sum_{i=1}^{I} A M_{K, i} \cdot X V M_{i, t}+V V M L_{t}=0 \text { for } t=1,, T(21)
\end{aligned}
$$

Note that the $\mathrm{K}$-th node is the mill.

11: Constraints for yard capacity at each period:

This requires that the volume of logs left over at the yard is less than its storing capacity, $Y C$.

$$
P V Y D_{t}+S V Y D_{t}+V V Y D_{t} \leq Y C \text { for } t=1,, T
$$

12: Constraints for an annual harvest flow for pulp, sawlog and veneer:

This requires that the annual harvest flow of each product is within a certain range.

$$
\begin{aligned}
& P V L_{t} \leq P V M L_{t}+\sum_{n=1}^{N} V P 3_{n, t} \leq P V U_{t} \text { for } t=1,, T \\
& S V L_{t} \leq S V M L_{t}+\sum_{n=1}^{N} V S 3_{n, t} \leq S V U_{t} \text { for } t=1,, T \\
& V V L_{t} \leq V V M L_{t}+\sum_{n=1}^{N} V V 3_{n, t} \leq V V U_{t} \text { for } t=1, T
\end{aligned}
$$

13: Constraints for harvest equipment utilities:

This requires that harvest equipment usage is within a certain range. It is neither economical nor convenient to buy or sell equipment frequently.

$$
H E L_{e, t} \leq \sum_{j=1}^{\prime} \sum_{o=1}^{o_{j}} E Q_{j, e, o} \cdot Z O_{j, o, t} \leq H E U_{e, t} \text { for } e=1,, E, t=1, T
$$

14: Constraints for availability of pulp, sawlog, and veneer from the third parties:

$$
\begin{aligned}
& \sum_{n=1}^{N} V P 3_{n, t} \leq P 3 U_{t} \text { for } t=1,, T \\
& \sum_{n=1}^{N} V S 3_{n, t} \leq S 3 U_{t} \text { for } t=1,, T \\
& \sum_{n=1}^{N} V V 3_{n, t} \leq V 3 U_{t} \text { for } t=1,, T
\end{aligned}
$$


Using the above constraints, an optimal harvest scheduling over the short time horizon was determined. Notice that since the time horizon is only 5 years, shorter than the minimum rotation age for Radiata pine, there is no reharvesting assumed in the above formulation. For a problem with a reharvesting option, decision variables for harvesting have to be modified as in Model I (JoHnson and STUART 1987) within the IP framework.

\section{MODEL DEVELOPMENT AND EXPERIMENTS}

In this section, the harvest scheduling system was constructed along with a transportation network problem over the short time horizon, then an example problem was presented to show how the $0-1$ integer restrictions affect the tactical harvest scheduling regime.

\section{Model Development}

To solve the proposed problem, a tactical harvest scheduling system with a transportąion network was constructed. The system consists of two parts, i.e., the Input File Generator and the IP optimizer. Like FORPLAN, which uses LINDO (SHRAGE 1987) as an optimizer, this system uses commercial software called CPLEX developed by CPLEX Optimization, Inc. (1994) to search for a final IP optimal solution. The Input File Generator formulates the problem in the MPS format retrievable by CPLEX. MPS format has been established on mainframe LP systems, and widely accepted as a standard to define not only LP problems but also IP problems. It is a column-oriented format, meaning that problems are specified by column.

The Input File Generator was made by the FORTRAN programming language. Fig. 1 shows the basic structure of the Input File Generator. The Input File Generator requires the following input information;

1. MPS output file name

2. the time horizon $(T)$ for planning

3. the number of harvest units $(J)$

4. the number of nodes $(K)$

5. the node number for the yard $(K-1)$

6. the node number for the mill $(K)$

7. the number of arcs (roads) $(I)$

8. the number of harvest equipment $(E)$

9. the limitation of equipment usage $\left(H E L_{e}, t, H E U_{e, t}\right)$

10. the number of the third parties to supply products $(N)$

11. a node-arc incidence matrix for a skidder or cable $(A)$

12. a node-arc incidence matrix for a mechanical harvester $(A M)$

13. forest growth data for harvest units

14. price data for forest products

15. discount rate $(r)$

16. yard capacity $(Y C)$

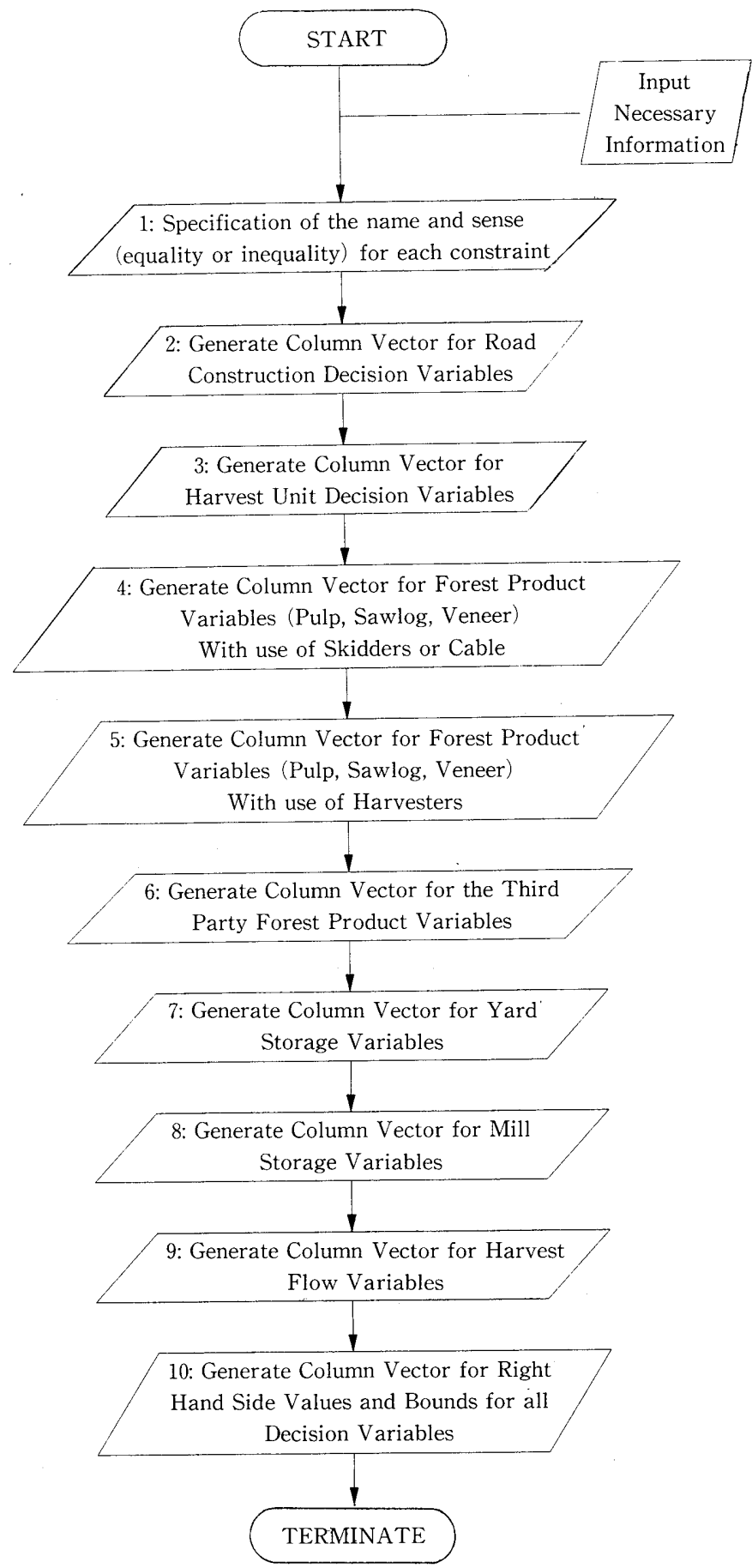

Fig. 1 Flowchart of the Input File Generator

Given the above information, the Input File Generator creates the MPS formatted input file for CPLEX in the order described in Fig. 1. The main components of the MPS file are the row names and sense (equality or inequality sign) for each constraint (the first part), the name assigned to each variable (column) and the nonzero constraint coefficients corresponding to that variable (from 
the second part to the ninth part), the names of right-hand side vectors and values for each constraint (row), and the limits for each variable (the tenth part). The resultant input file was retrieved into CPLEX to solve the problem.

\section{Data Description}

An example problem had six harvest units with sixteen nodes, one yard and one mill. The number of roads (arcs) was eighteen. Except the 18-th road, which connected the yard to the mill, all roads had to be built before any shipment of logs. Fig. 2 depicts the network of this problem. Harvest units were labeled by S1, S2, S3, S4, S5 and S6. Table 1 shows the initial condition of each harvest unit. Except for harvest unit S5, all harvest units were on a slope less than 35 degrees. For S5, 20.1ha out of 59.5 ha had a slope greater than 35 degrees. The slope is one of the important factors determining which harvest option should be implemented. If the slope is too steep, a harvester cannot be used. The proportion of veneer, sawlog, and pulp produced from a unit volume was assumed to be constant over time. No veneer was produced from the harvest units,
S1, S2, S3, S4, and S6. Only S5 could produce veneer. The price of each product was also assumed to be constant over time, and no real price premium was assumed The price of veneer was US\$80.00/ $\mathrm{m}^{3}$, the price of sawlog was US $\$ 50.00 / \mathrm{m}^{3}$, and the price of pulp was US $\$ 30.00 / \mathrm{m}^{3}$. As for the growth of a forest stand, the future mean annual increment was assumed to be $10 \mathrm{~m}^{3} / \mathrm{ha} / \mathrm{yr}$ if the stand stock was less than $300 \mathrm{~m}^{3} / \mathrm{ha}, 5 \mathrm{~m}^{3} / \mathrm{ha} / \mathrm{yr}$ if the stand stock was greater than $300 \mathrm{~m}^{3} / \mathrm{ha}$ and less than $500 \mathrm{~m}^{3} / \mathrm{ha}$, and $0 \mathrm{~m}^{3} /$ $\mathrm{ha} / \mathrm{yr}$ if the stand stock was greater than $500 \mathrm{~m}^{3} / \mathrm{ha}$. The weighting value for each stand was set to zero.

Logs from each harvest unit can be shipped in the following manner. All logs from S1 will be shipped to the 4 th node. In the case of S2, $20 \%$ of logs goes to the 2 nd node, and the other $80 \%$ goes to the 5 th node. All logs from S3 will be shipped to the 5 th node. Thirty percent of logs from S4 goes to the 6th node, and the rest goes to the 12th node. For S5, 20\% of logs are shipped to the 7 th node, $30 \%$ to the 11 th node, $35 \%$ to the 14 th node, and $15 \%$ to the 15 th node unless cable logging is applied. If the cable is used for this unit, all logs go to the 16th node. In the case of S6, $80 \%$ of logs go to the 8 th node, and the other $20 \%$ go to the 9 th

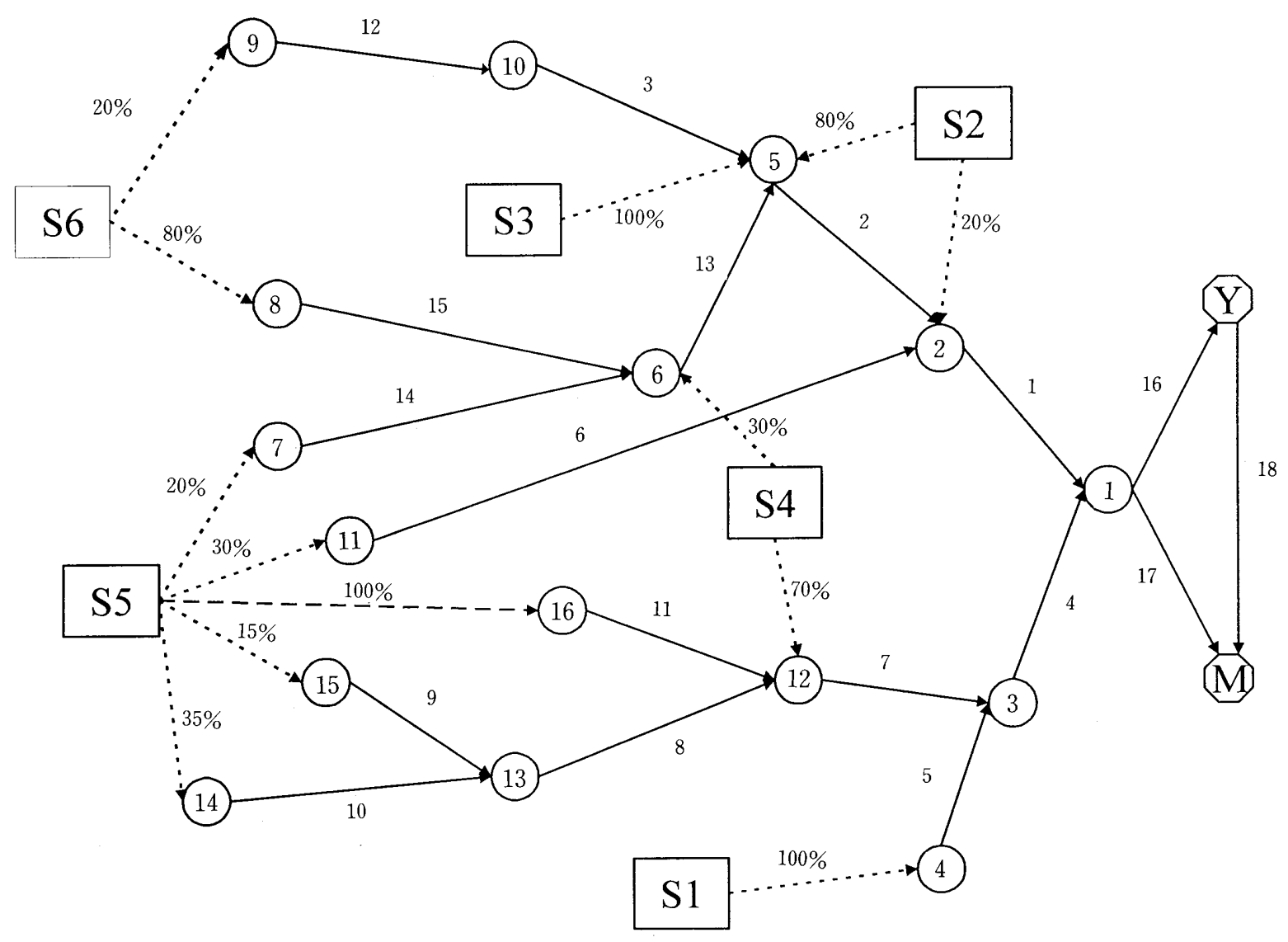

Fig. 2 Forest map and road network

: node, $\rightarrow$ : directional existing road, $\square:$ harvest unit, $\mathrm{Y}:$ yard, $\mathrm{M}:$ mill 
Table 1 Initial conditions of harvest units

\begin{tabular}{|c|c|c|c|c|c|c|c|}
\hline Harvest Unit & $\begin{array}{l}\text { Total } \\
\text { Area } \\
\text { (ha) }\end{array}$ & $\begin{array}{l}\text { Area } \\
\text { with } \\
\text { Slope } \\
>35^{\circ} \\
\text { (ha) }\end{array}$ & $\begin{array}{l}\text { Area } \\
\text { with } \\
\text { Slope } \\
\left\langle 35^{\circ}\right. \\
\text { (ha) }\end{array}$ & $\begin{array}{c}\text { Volume per } \\
\text { hectore } \\
\left(\mathrm{m}^{3} / \mathrm{ha}\right)\end{array}$ & $\begin{array}{c}\text { Veneer } \\
\text { Production } \\
\text { (\%/ha) } \\
\text { Price: } \\
\text { US } \$ 80.00 / \mathrm{m}^{3}\end{array}$ & $\begin{array}{c}\text { Sawlog } \\
\text { Production } \\
\text { (\%/ha) } \\
\text { Price: } \\
\text { US } \$ 50.00 / \mathrm{m}^{3}\end{array}$ & $\begin{array}{c}\text { Pulp } \\
\text { Production } \\
\text { (\%/ha) } \\
\text { Price: } \\
\text { US } \$ 30.00 / \mathrm{m}^{3}\end{array}$ \\
\hline $\mathrm{S} 1$ & 33.3 & 0 & 33.3 & 261.5 & 0 & 18.5 & 81.5 \\
\hline $\mathrm{S} 2$ & 16.8 & 0 & 16.8 & 343.2 & 0 & 1.7 & 98.3 \\
\hline $\mathrm{S} 3$ & 14.4 & 0 & 14.4 & 68.7 & 0 & 17.8 & 82.2 \\
\hline $\mathrm{S} 4$ & 12.6 & 0 & 12.6 & 149.9 & 0 & 27.2 & 72.8 \\
\hline S 5 & 59.5 & 20.1 & 39.4 & 352.5 & 4.3 & 11.91 & 83.8 \\
\hline S 6 & 20.1 & 0 & 20.1 & 417.6 & 0 & 13.5 & 86.5 \\
\hline
\end{tabular}

Note: Mean annual increment per ha is assumed to be:

$0 \mathrm{~m}^{3} / \mathrm{ha} / \mathrm{yr}$ if volume per ha is greater than $500 \mathrm{~m}^{3}$

$5 \mathrm{~m}^{3} / \mathrm{ha} / \mathrm{yr}$ if volume per ha is greater than $300 \mathrm{~m}^{3}$ and less than $500 \mathrm{~m}^{3}$

$10 \mathrm{~m}^{3} / \mathrm{ha} / \mathrm{yr}$ if volume per ha is less than $300 \mathrm{~m}^{3}$

Table 2 Connection among harvest units and nodes

\begin{tabular}{cccc}
\hline Harvest Unit & $\begin{array}{c}\text { Option } \\
\text { Number }\end{array}$ & Node & \% of Log Shipment \\
\hline S 1 & 1,2 & 4 & 100 \\
\hline S2 & 1 & 2 & 20 \\
& & 5 & 80 \\
\hline S 3 & 1 & 5 & 100 \\
\hline S 4 & 1,2 & 6 & 30 \\
& & 12 & 70 \\
\hline S 5 & 2 & 7 & 20 (Skidder) \\
& & 11 & 30 (Skidder) \\
& & 14 & 35 (Skidder) \\
& & 15 & 15 (Skidder) \\
\cline { 2 - 4 } & 1 & 16 & 100 (Cable) \\
\hline S6 & 1,2 & 8 & 80 \\
& & 9 & 20 \\
\hline
\end{tabular}

node (see Table 2 and Fig. 2).

Table 3 shows the relationship between nodes and roads with road construction costs (fixed costs) and $\log$ transportation costs (variable costs). Transportation costs were calculated by;

$\operatorname{Cost}\left(\mathrm{US} \$ / \mathrm{m}^{3}\right)=1.0186+0.0788 \times$ Road Length $(\mathrm{km})$

There was no road construction cost for the 18-th road. This road had been built already.

Table 4 shows the harvest options for each harvest unit, the harvest equipment used under each harvest option, and the setup costs. Harvest units S1, S4, S5, and S6 have two options, while S2 and S3 have only one option. A mechanical harvester can be used at S1, S4 and S6. A skidder can be used at S1, S3, S4, S5 and S6, while cable logging is required at $\mathrm{S} 2$, and can be used at $\mathrm{S} 5$.

The harvest equipment utility limitation is shown in Table 5. There is no limitation for use of a skidder. There are five cables and three mechanical harvesters. It is assumed that there is no yard capacity limitation to hold logs over time.

\section{Model Experiments}

In this study, five problems were solved. The first two problems, Problems 1 and 2 , did not contain the $0-1$ integer requirements. That is, the road construction costs were not taken into consideration, and area to be harvested was allowed to be any nonnegative real value less than 1 . Problem 1 did not have the harvest flow constraints, either. Problem 2 was the same as the first, but with the harvest flow constraints. Next two problems, Problems 3 and 4 , had the 0-1 integer requirements for the road construction decision variables, but no $0-1$ integer requirements for the harvest decision variables. Problem 3 did not have the harvest flow constraints, while Problem 4 did. The last problem, Problem 5, was the same as the third problem with the $0-1$ integer requirements for the harvest decision variables. Since the number of harvest units in this example was few, there was no feasible solution satisfying the harvest flow constraints with all $0-1$ integer restrictions. Thus, the harvest flow constraints were not embedded into Problem 5.

The harvest flow constraints used in Problems 2 and 4 were set to allow (10\% fluctuation of the flow over the time horizon. The time horizon was set to 5 periods, where 1 period was 1 year. A discount rate of $5 \%$ was used. A Pentium $100 \mathrm{MHz}$ IBM compatible $\mathrm{PC}$ was used for the calculation. Table 6 shows a summary of the results.

The first problem, Problem 1, had 575 continuous 
Table 3 Node-Arc connection

\begin{tabular}{|c|c|c|c|c|c|}
\hline Arc \# & $\begin{array}{l}\text { From } \\
\text { Node }\end{array}$ & $\begin{array}{c}\text { To } \\
\text { Node }\end{array}$ & $\begin{array}{c}\text { Fixed Cost } \\
\text { (US\$) }\end{array}$ & $\begin{array}{l}\text { Variable Cost* } \\
\left(\mathrm{US} \$ \mathrm{~m}^{3}\right)\end{array}$ & $\begin{array}{c}\text { Length } \\
(\mathrm{km})\end{array}$ \\
\hline 1 & 2 & 1 & 10815 & 1.05 & 0.35 \\
\hline 2 & 5 & 2 & 22445 & 1.07 & 0.67 \\
\hline 3 & 10 & 5 & 44220 & 1.12 & 1.32 \\
\hline 4 & 3 & 1 & 21630 & 1.07 & 0.7 \\
\hline 5 & 4 & 3 & 24720 & 1.03 & 0.2 \\
\hline 6 & 11 & 2 & 60255 & 1.17 & 1.95 \\
\hline 7 & 12 & 3 & 24480 & 1.08 & 0.8 \\
\hline 8 & 13 & 12 & 7650 & 1.04 & 0.25 \\
\hline 9 & 15 & 13 & 15300 & 1.06 & 0.5 \\
\hline 10 & 14 & 13 & 1530 & 1.02 & 0.05 \\
\hline 11 & 16 & 12 & 3060 & 1.03 & 0.1 \\
\hline 12 & 9 & 10 & 6732 & 1.04 & 0.22 \\
\hline 13 & 6 & 5 & 12240 & 1.05 & 0.4 \\
\hline 14 & 7 & 6 & 13770 & 1.05 & 0.45 \\
\hline 15 & 8 & 6 & 19890 & 1.07 & 0.65 \\
\hline 16 & 1 & 17 (YARD) & 77050 & 4.19 & 40.3 \\
\hline 17 & 1 & 18 (MILL) & 77050 & 8.37 & 93.3 \\
\hline 18 & 17 (YARD) & 18 (MILL) & 0 & 9.00 & 101.3 \\
\hline
\end{tabular}

* : Variable costs were calculated by

Cost $\left(\mathrm{US} \$ / \mathrm{m}^{3}\right)=1.0186+0.0788 \mathrm{D}(\mathrm{km})$

where $D$ is a length of road

Table 4 Harvest options at each harvest unit

\begin{tabular}{|c|c|c|c|c|c|}
\hline Harvest Unit & Option Number & Skidder & Cable & Harvester & $\begin{array}{l}\text { Total Setup } \\
\text { Costs (US\$) }\end{array}$ \\
\hline \multirow[t]{2}{*}{$\mathrm{S} 1$} & 1 & $\mathrm{x}$ & & & 650 \\
\hline & 2 & & & $\mathrm{x}$ & 500 \\
\hline $\mathrm{S} 2$ & 1 & & $\mathrm{x}$ & & 800 \\
\hline $\mathrm{S} 3$ & 1 & $\mathrm{x}$ & & & 650 \\
\hline \multirow[t]{2}{*}{$\mathrm{S} 4$} & 1 & $\mathrm{x}$ & & & 650 \\
\hline & 2 & & & $\mathrm{x}$ & 500 \\
\hline \multirow[t]{2}{*}{ S 5} & 1 & & $\mathrm{x}$ & & 800 \\
\hline & 2 & $\mathrm{x}$ & & & 650 \\
\hline \multirow[t]{2}{*}{ S 6} & 1 & $\mathrm{x}$ & & & 650 \\
\hline & 2 & & & $\mathrm{x}$ & 500 \\
\hline
\end{tabular}

Table 5 Harvest equipment utility

\begin{tabular}{cccc}
\hline & Number of Machines & $\begin{array}{c}\text { Harvest Capacity } \\
\mathrm{m}^{3} / \text { machine } / \text { month }\end{array}$ & $\begin{array}{c}\text { Cost } \\
\left(\mathrm{US} \$ / \mathrm{m}^{3}\right)\end{array}$ \\
\hline Cable & 5 & 1800 & 9.7 \\
Skidder & no limitation & 2200 & 8.5 \\
Harvester & 3 & 5000 & 6.0 \\
\hline
\end{tabular}


Table 6 Summary of results from 5 problems

\begin{tabular}{rrrrrrrr}
\hline & $\begin{array}{c}\text { Calculation } \\
\text { Time(second) }\end{array}$ & $\begin{array}{c}\text { Objective } \\
\text { Value(US\$) }\end{array}$ & $\begin{array}{c}\text { Number of } \\
\text { Iterations }\end{array}$ & $\begin{array}{c}\text { Number of } \\
\text { Branches }\end{array}$ & $\begin{array}{c}\text { Number of } \\
\text { Constraints }\end{array}$ & $\begin{array}{c}\text { Number of } \\
\text { Nonzero } \\
\text { Variables }\end{array}$ & $\begin{array}{c}\text { Number of } \\
\text { Binary } \\
\text { Variables }\end{array}$ \\
\hline Problem 1 & 0.22 & $900,487.40$ & 18 & not available & 536 & 575 & not available \\
Problem 2 & 0.22 & $877,259.15$ & 64 & not available & 566 & 578 & not available \\
Problem 3 & 116.49 & $556,125.02$ & 39,452 & 5,238 & 728 & 575 & 85 \\
Problem 4 & 27.68 & $531,071.20$ & 9,813 & 559 & 758 & 578 & 85 \\
Problem 5 & 555.35 & $460,787.72$ & 153,342 & 24,164 & 728 & 525 & 135 \\
\hline
\end{tabular}

Note : Problem 1: No integer restriction without harvest flow constraints

Problem 2: No integer restriction with harvest flow constraints

Problem 3: Integer restriction on road construction variables without harvest flow constraints

Problem 4: Integer restriction on road construction variables with harvest flow constraints

Problem 5: Integer restriction on road construction and harvest unit variables without harvest flow constraints

variables with 536 constraints. The computational time to search for an optimal solution was 0.22 seconds with 18 iterations. The optimal objective value was US $\$ 900,487.40$. Since no harvest flow constraint was considered, harvest took place at periods, 1,2 , and 5 . Veneer was available only at period 1 . The harvest decision variables were 1 for S2, S3, S4 and S6. A harvester was used at S1 at period 1 and 2 , and at $\mathrm{S} 4$ at period 5 .

The second problem, Problem 2, had 578 continuous variables with 566 constraints. Because of the additional harvest flow constraints, three variables were added as an even-flow variable for pulp, sawlog, and veneer. The computational time was also 0.22 seconds with 64 iterations. The optimal objective value became US\$877,259.15, less than that of the first problem. This difference of US $\$ 23,228.25$, can be regarded as a cost of restricting the harvest flow. Only the harvest decision variables for S2 and S3 were 1. A harvester was used over the entire time horizon.

The third problem, Problem 3 , had 575 variables, the same as Problem 1, 85 out of which were $0-1$ integer. The total number of constraints was 728 . It took 116.49 seconds to solve the problem with 39,452 iterations under 5,238 branches. The optimal objective value was US\$556, 125.02 . Although the harvest flow constraints were not taken into account, there was the flow over the entire time horizon. However, veneer was not available at period 5 . Only the harvest decision variable for S4 was not 1 , and the others became 1. A harvester was used at period 4 and 5 only. The number of roads constructed was 12 . Four roads were built at period 1 , two at period 3 , two at period 4 and four at period 5 .

Introducing the harvest flow constraints to the third problem, Problem 4, had 578 variables with the same number of $0-1$ integer variables as in the third problem. The number of constraints was 758 . The computational time was 27.68 seconds with 9,813 iterations under 559 branches. The optimal objective value was US\$531,071.20. Reduction in the computational time was probably due to the harvest flow constraints. Intermediate solutions during the branching operation would become infeasible at an early stage of branching because of the flow constraints, resulting in less iterations and branches than the third problem. Only the harvest decision variable for S3 became 1. A harvester was used at period $2,3,4$ and 5 . The number of roads constructed was 12 , the same as the third problem. However, seven roads were built at period 1, two at period 2 and three at period 4 . This is because of the dispersion effect of the harvest flow constraints on the harvesting regime. That is, in order to spread harvest flow over time, more roads were constructed at earlier periods than in Problem 3.

The last problem, Problem 5, was the same as the third problem except the number of integer variables. The number of integer variables was 135 . The computational time was 555.35 seconds with 153,342 iterations under 24,164 branches. The optimal objective value was further reduced to US $\$ 460,787.72$. Compared to the third problem, the objective value was US $\$ 95,337.30$ less, due to the $0-1$ integer restrictions on the harvest decision variables. Under no harvest flow constraints, harvest took place at period 4 and 5 . At period $4, \mathrm{~S} 1, \mathrm{~S} 2$ and S5 were harvested, while others were harvested at period 5 . Veneer was available at period 4 . Sixteen roads were built, thirteen of which were at period 4 and the rest was at period 5 . A harvester was used for S1 at period 4, and S4 and S6 at period 5 .

\section{DISCUSSION AND CONCLUSIONS}

As can be seen in the above results, including the harvest flow constraints reduced the objective value by 30 to $40 \%$. Since it was impossible to convert road construc- 
tion costs (fixed costs) into variable costs for transportation by an amount of volume to be shipped, direct comparison could not be achieved precisely among the continuous problems and the IP problems. However, we can say that road construction costs could make a difference to the solutions. For instance, S6 in the LP problem (Problem 1) was harvested at period 1 , compared to period 5 in the IP problem (Problem 3). This may be due to adding the road construction constraints. The same things can be said about harvest unit S1. It was harvested at the early period in the LP problem, and at period 4 in the IP problem. There are, of course, the same solutions for some harvest decision variables, such as $\mathrm{S} 3$ and $\mathrm{S} 4$, which were harvested at period 5 for both problems. The same tendency can be observed for the other problems with harvest flow constraints. The harvest unit S6 tended to be harvested at the early period for the continuous problem, while it was harvested at the late period for the IP problem. A delay in harvest is most likely due to the effect of discounting road construction costs on the objective function. The later the construction, the lower the costs on the basis of present net value.

Table 7 shows the effect of the integer restrictions on the objective value. Problem numbers with ' represent the solutions from the corresponding problem after subtracting imposed road construction costs. When road construction costs were calculated for the solution of Problem 1, the total road construction costs were US $\$ 442,837.00$, which was $42 \%$ higher than that of Problem 3, US $\$ 312,652.30$ (see Problem 1' column in Table 7). Thus, the resultant objective value became US $\$ 457,650.40$, which was $18 \%$ lower than the corresponding optimal solution of Problem 3. As can be seen in the cash flow at period 1 of Problem
1', the cash flow decreased from US $\$ 781,292.80$ to US $\$ 338,455.80$, a difference equivalent to the total road construction costs. This implies that all road construction took place at period 1. On the other hand, when the integer restriction was imposed on road construction in Problem 3 , roads were constructed at periods $1,3,4$ and 5 . This result implies that if no integer restrictions were applied, road construction would tend to take place in early periods since the objective function does not include any effect from road construction costs, but if road construction was treated as an integer variable, costs could be spread over different periods.

The 0-1 integer restrictions on the harvest decision variables further reduced the objective value by $17 \%$, and increased the road construction costs by $20 \%$. This led to no cash flow or no harvest at periods 1,2 and 3 . Under the harvest flow constraints, the road construction costs for Problem 2 would become US\$344,332.00 (Problem 2') and be charged at period 1 . Although this value was $4 \%$ higher than that of Problem 4, the objective value after subtracting the costs was slightly higher than the objective value of Problem 5. This inconsistency resulted from the infeasibility of the derived solution of Problem 2' because of the nonnegative cash flow constraints, as seen at period 1 . Since all necessary roads were built at period 1 , the costs were charged at period 1 , resulting in negative final cash flow.

It is important to note from the above discussion that solutions from the LP formulation could be unexpectedly infeasible or inferior solutions to those from the IP formulation. Since the tactical harvest scheduling is usually a short-term problem, any error in the final regime could result in serious costs on the schedule. Therefore, formula-

Table 7 Effect of integer restriction on decision variables

\begin{tabular}{|c|c|c|c|c|c|c|c|c|}
\hline & & \multicolumn{4}{|c|}{ Without Harvest Flow Constraints } & \multicolumn{3}{|c|}{ With Harvest Flow Constraints } \\
\hline & & Problem 1 & Problem 1' & Problem 3 & Problem 5 & Problem 2 & Problem 2' & Problem 4 \\
\hline \multirow{2}{*}{\multicolumn{2}{|c|}{$\begin{array}{r}\text { Objective Value (US\$) } \\
\text { Road Construction Costs } \\
\text { (US\$) }\end{array}$}} & $900,487.40$ & $457,650.40$ & $556,125.02$ & $460,787.72$ & $877,259.15$ & $532,927.15$ & $531,071.20$ \\
\hline & & not available & $442,837.00$ & $312,652.30$ & $376,981.80$ & not available & $344,332.00$ & $329,839.80$ \\
\hline \multirow{5}{*}{$\begin{array}{c}\text { Cash Flow } \\
\text { (US\$) }\end{array}$} & Period 1 & $781,292.80$ & $338,455.80$ & $37,136.50$ & 0 & & $-130,170.40$ & $9,718.36$ \\
\hline & Period 2 & $50,596.82$ & $50,596.82$ & $163,341.30$ & 0 & $201,056.60$ & $201,056.60$ & $98,756.22$ \\
\hline & Period 3 & 0 & 0 & $112,085.20$ & 0 & $177,570.80$ & $177,570.80$ & $185,982.40$ \\
\hline & Period 4 & 0 & 0 & $126,419.80$ & $345,161.00$ & $188,061.10$ & $188,061.10$ & $129,474.30$ \\
\hline & Period 5 & $86,309.16$ & $86,309.16$ & $185,417.90$ & $197,657.90$ & $180,007.00$ & $180,007.00$ & $178,379.10$ \\
\hline
\end{tabular}

Note : Problem 1: No integer restriction without harvest flow constraints Problem 1': Road construction costs charged to a solution from Problem 1 Problem 2: No integer restriction with harvest flow constraints Problem 2': Road construction costs charged to a solution from Problem 2 Problem 3: Integer restriction on road construction variables without harvest flow constraints Problem 4: Integer restriction on road construction variables with harvest flow constraints Problem 5: Integer restriction on road construction and harvest unit variables without harvest flow constraints 
tion of the problem should not be misspecified.

From the viewpoint of the computational time, a major issue for the IP problem has been the computational burden. While the proposed continuous problems were solved in less than a second, it took 100 to 600 times longer to solve the corresponding IP problems with integer variables for the harvest decision variables. For the last problem, where both the road construction and harvest decision variables were treated as $0-1$ integer, it took about 2500 times longer. The computational time of the IP problems is highly affected by the "tightness" of the constraints. The tighter the problem, the faster the solution is found (WILliams 1974). Since the branch-and-bound algorithm starts branching from the LP relaxed solution, a final solution could be found at the early stage of branching if the number of integer solutions in the LP relaxed problem is large. For the first two IP problems, we can say that the constraints for the $0-1$ integer variables were very tight, because of the combination of the second constraint (road linkage constraints for one-directional transshipment), the third constraint (simultaneous log transportation constraints), and the fourth constraint (harvest unit and road linkage constraints). Our other experiments showed that without these three constraints, applying the fifth constraint (constraints for road construction before shipping logs) to all roads took much more computational time to find the final solution compared to the times shown in Table 6.

If the computational burden cannot be resolved by reformulating the $0-1$ integer problem, a prior knowledge about the largest lower bound of the objective value would be helpful. The lower bound is the objective value of one of the feasible solutions. Thus, the optimal objective value has to be equal to or greater than the lower bound. Such a feasible solution can be found by using heuristics. For a larger problem with the $0-1$ integer requirements for both road construction and harvest decision variables, heuristics may play an important role in finding "good" feasible solutions.

\section{ACKNOWLEDGEMENT}

This research was conducted while the author was Visiting Professor at Instituto de Manejo Forestal,Universidad Austral de Chile in 1993. The author thanks Dr. Gonzalo L. Paredes V. and Mr. Mauricio Ruiz-Tagle at Universidad Austral de Chile for their help on the project.

\section{LITERATURE CITED}

Clements, S.E., Dallain, P.L. and Jamnick, M.S., (1990): An operational spatially constrained harvest scheduling model. Can. J. For.
Res. 20:1438-1447

CPLEX Optmization Inc., (1994): Using the CPLEX linear optimizer. CPLEX Optmization Inc., NV, 130pp

DAKIN, R.J., (1965): A tree search algorithm for mixed integer programming. Comput. Oper. Res. 13:551-562

Johnson, K.N. and Jones, D.B., (1979): A user's guide to multiple use -sustained yield resource scheduling calculation (MUSYC). Mimeo. Timber management, USDA Forest Service, Fort Collings, Colorado, 242pp

Johnson, K.N. and STUART, T.W., (1987): FORPLAN Version 2: Mathematical programmer's guide. USDA For. Serv. Land Manage. Plan. Syst. Sect., Washington DC, 158pp

Kirby, M.W., Wong, P., Hager, W.A. and Huddleston, M.E., (1980): A guide to the integrated resources planning model. USDA For. Serv., Berkeley, CA, 221pp

Konohira, Y., (1982): In-place timber harvest scheduling by zero-one integer program. Bulletin of the Shinshu University Forests. No19: $1-66$

LAND, A.H. and DoIG, A.G., (1960): An automatic method for solving discrete programming problems. Econometrica 28:497-520

NAvon, D.I., (1971): TimberRAM: A long range planning method for commercial timber lands under multiple-use management. USDA For. Serv. Pap. PSW-70, 22pp

Nelson, J.D. and Brodie, J.D., (1990): Comparison of a random search algorithm and mixed integer programming for solving area-based forest plans. Can. J. For. Res. 20:934-942

Nelson, J.D., Brodie, J.D. and Sessions, J., (1991): Integrating shortterm, area-based logging plans with long-term harvest schedules. For. Sci. 37:101-121

RoIse, J.P., (1990): Multicriteria nonlinear programming for optimal spatial allocation of stands. For. Sci. 36:487-501

SHra(ie, L., (1987): User's manual for linear, integer and quadratic programming with LINDO. The Scientific Press, CA, 96pp

SEssions, J. and Sessrons, J.B., (1988): SNAP - a scheduling and network analysis program for tactical harvest planning. Proceedings International Mountain Logging and Pacific Northwest Skyline Symposium. Oregon State Univ., Corvallis, OR: 71-75

ToRres, R. J.M., (1989): The use of relaxation to solve harvest scheduling problems with flow, wildlife habitat and adjacency constraints. Ph.D. Diss. Dept. of For. Resour., Oregon State Univ., Corvallis, OR, $182 \mathrm{pp}$

Williams, H.P., (1974): Experiments in the formulation of integer programming problems. In Approaches to integer programming. Edited by M.L. Balinski. North-Holland, Amsterdam. Math. Progr. Study 8: 82-114

Yoshimoto, A. and Brodie, J.D., (1994): Short- and long-term impacts of spatial restrictions on harvest scheduling with reference to riparian zone planning. Can. J. For. Res. 24:1617-1628

Yoshimoto, A., Brodie, J.D., and Sessions, J., (1994): A new heuristic to solve spatially constrained long-term harvest scheduling problems. For. Sci. 40:365-396 